\title{
Pra Desain Pabrik Margarin dari Kacang Tanah dengan Proses Hidrogenasi Berkapasitas 3.856 Ton/Tahun
}

\author{
Lalitya Syifalia, Abdul Karim Amarullah, Setiyo Gunawan, dan Hakun Wirawasista Aparamarta \\ Departemen Teknik Kimia, Fakultas Teknologi Industri, Institut Teknologi Sepuluh Nopember (ITS) \\ e-mail: gunawan@chem-eng.its.ac.id
}

\begin{abstract}
Abstrak-Dalam penelitian ini telah dilakukan perancangan pabrik margarin dari kacang tanah dengan proses hidrogenasi berkapasitas produk sebesar 3.856 ton/tahun, waktu operasi 24 jam dan 330 hari/tahun. Tujuan perancangan pabrik margarin ini adalah untuk memenuhi 5\% dari total kebutuhan margarin dalam negeri. Pabrik margarin ini direncanakan akan didirikan di Kabupaten Tuban, Jawa Timur. Alasan pemilihan tempat ini adalah karena potensi bahan baku yang tersedia mampu memenuhi kebutuhan ketersediaan bahan baku kacang tanah untuk pabrik margarin, dekat dengan pasar, dan saranaprasarana yg mendukung. Pembuatan margarin dari minyak kacang tanah ini dipilih proses hidrogenasi. Proses dalam pabrik ini terdiri dari 4 tahap utama yaitu tahap persiapan bahan baku, tahap pressing, pemurnian, hidrogenasi, dan emulsifikasi. Sumber dana investasi berasal dari modal sendiri sebesar $70 \%$ biaya investasi dan modal pinjaman sebesar $30 \%$ biaya investasi dengan bunga sebesar $10,25 \%$ per tahun. Dari analisis perhitungan ekonomi didapat hasil investasi Rp 139.24.579.000,00, dengan IRR 14,4 \%, POT 6 tahun dan BEP $62,05 \%$.
\end{abstract}

Kata Kunci_ - Hidrogenisasi, Kacang Tanah, Margarin, Pabrik.

\section{PENDAHULUAN}

$\mathrm{P}$ EMBANGUNAN industri ditujukan untuk memperkokoh struktur ekonomi nasional dengan keterkaitan yang kuat dan saling mendukung antar sektor, meningkatkan daya tahan perekonomian nasional, memperluas lapangan kerja dan kesempatan usaha sekaligus mendorong berkembangnya kegiatan berbagai sektor pembangunan nasional lainnya. Kemajuan industri di Indonesia dewasa ini cukup besar, terutama dalam bidang pemanfaatan hasil-hasil pertanian, perkebunan, dan berbagai jenis hasil hutan.

Subsektor industri pangan merupakan salah satu subsektro yang pembangunannya berkembang dengan pesat saat ini. Hal ini terjadi karena kebutuhan akan barang-barang hasil industri pangan terus meningkat sejalan dengan perkembangan pembangunan itu sendiri. Salah satu jenis produksi industri yang berkembang pesat dan selalu dibutuhkan akibat permintaan dari masyarakat adalah industri margarin.

Margarin merupakan salah satu produk emulsi air dalam minyak, yaitu fase air berada dalam fase minyak dengan raiso lemak dan air sekitar 80\%: 20\%. Margarin umumnya dibuat dari minyak nabati, misalnya minyak kelapa, minyak kelapa sawit, minyak kedelai dan minya biji kapas. Ciri-ciri margarin yang paling menonjol adalah bersifat plastis, padat pada suhu ruang, agak keras pada suhu rendah, teksturnya mudah dioleskan, serta segera dapat mencair di dalam mulut [1].
Dalam bidang pangan penggunaan margarin telah dikenal secara luas terutama baking dan cooking yang bertujuan memperbaiki tekstur dan menambah cita rasa pangan Margarin juga sering digunakan untuk keperluan menumis atau menggoreng.

Tingginya permintaan pasar akan margarin di Indonesia ditunjukkan dengan kapasitas produksi margarin nasional yang cenderung naik dari tahun ke tahun. Pada tahun 2014 produksi margarin Indonesia mencapai 102.484,9 ton/tahun. Nilai kapasitas produksi yang tinggi ini belum cukup memenuhi kebutuhan margarin di Indonesia sehingga perlu dipenuhi dengan melakukan impor sebesar $2.164,5$ ton dari berbagai negara pada tahun tersebut [2].

Konsumsi margarin rata-rata per kapita oleh penduduk Indonesia cukup tinggi sehingga hal ini akan menambah peluang akan produksi margarin. Pabrik direncanakan beroperasi pada tahun 2020 untuk memenuhi 5\% dari total kebutuhan margarin dalam negeri sebesar 3.856 ton/tahun yang direncanakan beroperasi 24 jam dan 330 hari/tahun.

Selama ini bahan baku yang sering digunakan dalam pembuatan margarin adalah kelapa sawit. Penanaman kelapa sawit sendiri sebenarnya tidak ramah lingkungan karena harus mengorbankan lahan hutan alam dan lahan gambut demi perkebunan baru. Untuk menekan konsumsi kelapa sawit yaitu dengan mengganti bahan baku pembuatan margarin dengan kacang tanah. Pemilihan bahan baku ini didasarkan atas pertimbangan bahwa minyak kacang tanah memiliki kandungan lemak yang tinggi dan nilai gizi yang baik. Selain itu, produktivitas kacang tanah juga semakin tinggi dan jumlahnya sangat banyak di Indonesia dengan produksi tahunan tertinggi di Indonesia adalah dari Provinsi Jawa Timur, yaitu 193.703 ton/tahun. Kabupaten Tuban direncanakan menjadi tempat pendirian pabrik karena potensi bahan baku yang tersedia mampu memenuhi kebutuhan ketersediaan bahan baku kacang tanah untuk pabrik margarin (produksi kacang tanah 52.614 ton/tahun), dekat dengan pasar, dan sarana-prasarana yg mendukung [3].

Bentuk badan perusahaan dalam Pabrik Margarin dari Kacang Tanah ini dipilih Perseroan Terbatas (PT). Bentuk organisasi merupakan organisasi sistem garis dan staf dengan jumlah tenaga kerja yang dibutuhkan sebanyak 124 orang.

Secara garis besar tahapan proses pada pabrik margarin ini terdiri dari dari 4 tahap utama yaitu tahap pressing, pemurnian, hidrogenasi, dan emulsifikasi. Tahap pressing yaitu proses pengambilan minyak dari biji dilakukan dengan tekanan yang sangat tinggi sehingga minyak yang dihasilkan semaksimal mungkin. 


\section{II.URAIAN PROSES}

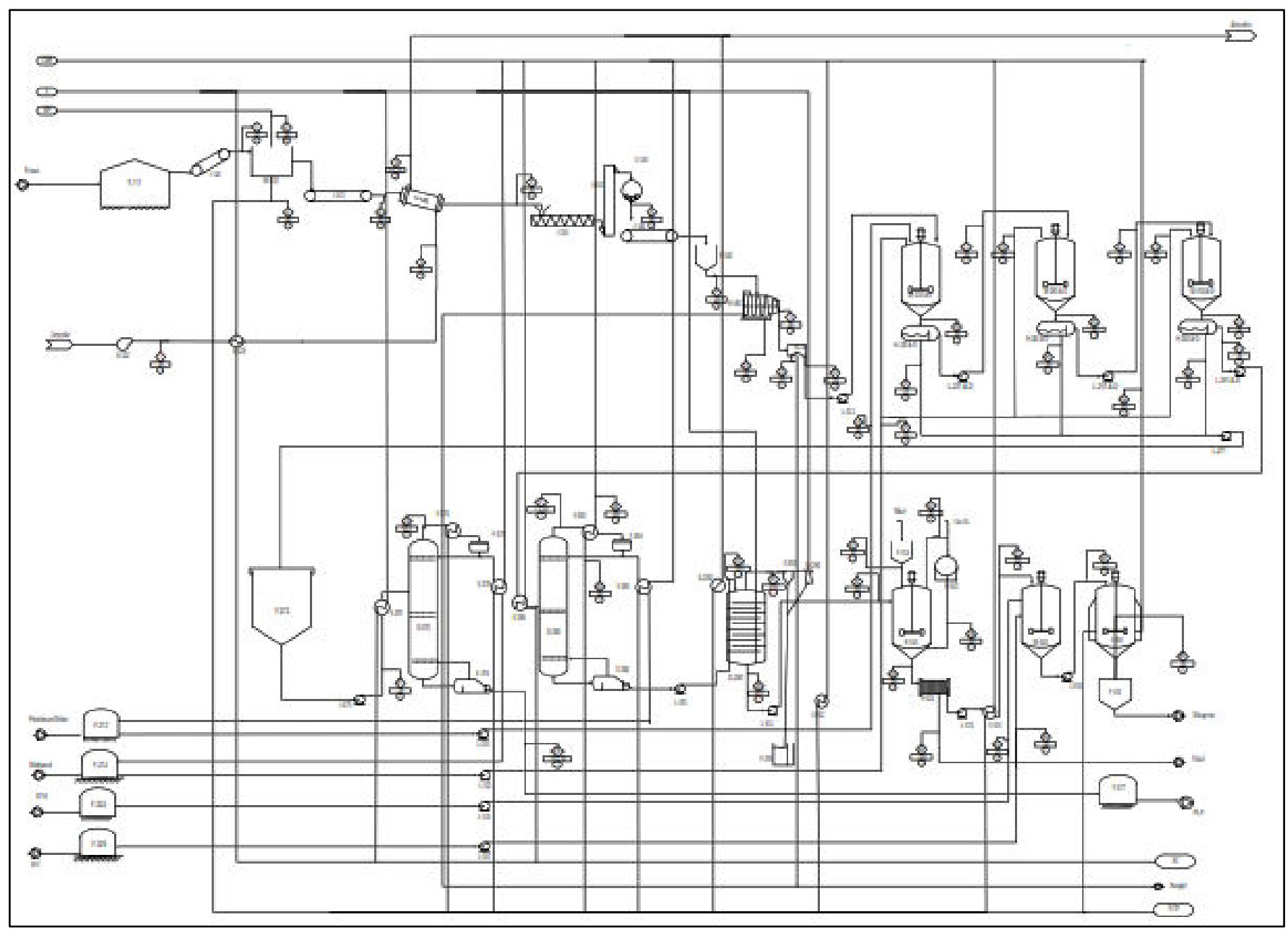

Gambar 1. Process Flow Diagram Pabrik Margarin.

Tahap pressing yaitu proses pengambilan minyak dari biji dilakukan dengan tekanan yang sangat tinggi sehingga minyak yang dihasilkan semaksimal mungkin. Pertama-tama biji kacang tanah yang ditempatkan pada gudang penampungan dipindahkan dengan belt convenyor ke dalam rotary dryer untuk dikeringkan. Belt conveyor yang digunakan bertipe continuous flow conveyor. Rotary dryer berfungsi untuk mengurangi kadar air dalam kacang tanah. Kondisi operasi pada operasi ini menggunakan suhu $75^{\circ} \mathrm{C}$ dan tekanan $1 \mathrm{~atm}$. Setelah itu, kacang tanah kemudian diangkut menggunakan bucket elevator dari rotary dryer ke dalam ball mill. Ball mill berfungsi untuk menghaluskan (menyeragamkan) ukuran partikel kacang tanah (ukuran sekitar 35 mesh). Kacang tanah yang sudah halus kemudian diangkut menggunakan belt conveyor dari ball mill ke dalam screw expeller pressing pada suhu $35^{\circ} \mathrm{C}$ dan $1 \mathrm{~atm}$. Minyak hasil pengepresan dialirkan dengan menggunakan pompa dari screw expeller pressing ke dalam mixer I. Sedangkan bungkil dari screw expeller pressing ditempatkan ke dalam bak penampung bungkil.

Selanjutnya pada tahap pemurnian, Minyak hasil pressing/ekstraksi (crude oil) mengandung triasilgliserol (TAG), asam lemak bebas (free fatty acid atau FFA), dan senyawa lainnya. Agar bisa digunakan menjadi minyak goreng (edible oil) kadar FFA dalam minyak harus kurang dari $0,3 \%$. Tahap pemurnian bertujuan untuk mengurangi kadar FFA menjadi kurang dari $0,3 \%$ dan memurnikan minyak. Pada tahap ini, pemurnian dilakukan dengan cara multistage batchwise extraction yaitu ekstraksi menggunakan solvent polar dan non-polar, untuk memisahkan senyawa polar dan non-polar yang terdapat dalam crude oil, sehingga didapatkan dua fraksi, polar dan non-polar. Senyawa yang termasuk nonpolar antara lain hidrokarbon dan TAG, sedangkan senyawa yang termasuk polar antara lin diasilgliserol (DAG), monoasilgliserol (MAG), FFA, dan senyawa lainnya. Solvent yang digunakan dalam tahap ini adalah metanol sebagai solvent polar dan petroleum eter sebagai solvent non-polar dengan perbandingan minyak terhadap solvent adalah 1:5 dan perbandingan antara metanol dan petroleum eter adalah 1:3 [4].

Di dalam mixer I, minyak akan dicampur dengan solvent metanol dan petroleum eter dan setelah itu diaduk selama 15 menit pada suhu dan tekanan ruangan. Setelah pengadukan selesai, campuran minyak dengan solvent akan dialirkan menuju decanter untuk pemisahan kedua fraksi. Senyawa nonpolar terdapat pada fraksi bagian atas dan senyawa polar terdapat pada fraksi bagian bawah. Setelah pemisahan selesai, ekstrak yang berupa senyawa non-polar akan memasuki mixer II dimana fraksi non-polar (fraksi petroleum eter) diekstrak kembali menggunakan metanol pada suhu dan tekanan ruangan. Ekstraksi dilakukan dalam 3 tahap (3 stages) agar 
diperoleh kadar TAG yang tinggi. Hasil dari ekstraksi 3 tahap kemudian dilakukan distilasi untuk masing-masing fraksi (fraksi polar dan non-polar) untuk mendapatkan refined peanut oil dan untuk mendapatkan solvent untuk direcycle. Dari proses permurnian tersebut, didapatkan minyak dengan kadar TAG sebesar $98,8 \%$ dan kadar FFA sebesar $0,35 \%$. Minyak selanjutnya menuju proses deodorisasi yang bertujuan untuk menghilangkan bau dan rasa yang tidak enak pada minyak. Prinsip deodorisasi dilakukan dengan cara penyulingan minyak menggunakan uap panas (steam) dalam tekanan atmosfer atau tekanan vakum [5]. Operasi dilakukan pada keadaan vakum dengan tujuan untuk menguapakan sebagian air yang terkandung dalam minyak, karena uap air ini akan mendegradasi trigliserida menjadi asam lemak bebas. Selain itu kondisi vakum juga bertujuan untuk menurunkan titik didih dari minyak karena minyak dapat rusak pada suhu tinggi [6]. Pada proses deodorisasi, minyak dari hasil distilasi dipompa dengan menggunakan pompa ke tangki deodorisasi. Proses deodorisasi terjadi pada suhu tinggi dan pada tekanan rendah. Kondisi operasi pada proses ini adalah suhu $250^{\circ} \mathrm{C}$ dan tekanan $2 \mathrm{KPa}$ sambil dialiri steam untuk mengangkut senyawa yang dapat menguap. Sehingga pada suhu tersebut fraksi bukan minyak telah teruapkan seperti air, zat penyebab bau, FFA, dan impurities yang lain karena pada umumnya zatzat tersebut lebih volatile daripada minyak. Setelah proses deodorisasi, minyak dialirkan ke dalam cooler untuk menurunkan suhu dari $250^{\circ} \mathrm{C}$ menjadi $90^{\circ} \mathrm{C}$ [5].

Tahap selanjutnya adalah tahap hidrogenasi, bertujuan untuk menjenuhkan ikatan rangkap dari asam lemak pada minyak atau lemak. Proses hidrogenasi dilakukan dengan menggunakan hidrogen murni dan ditambahkan serbuk nikel sebagai katalisator. Mekanisme proses hidrogenasi :

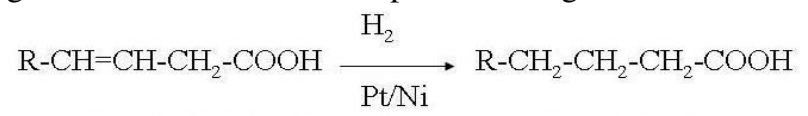

asam lemak tidak jenuh asam lemak jenuh

Reaksi pada proses hidrogenasi terjadi pada permukaan katalis yang mengakibatkan reaksi antara molekul-molekul minyak dengan gas hydrogen. Nikel merupakan katalis pada umumnya yang digunakan untuk proses hidrogenasi. Nikel lebih ekonomis dan efisien dibanding logam lainnya. Proses hidrogenasi merubah asam linoleat menjadi asam oleat dan kemudian asam oleat diubah menjadi asam stearat [5].

Hidrogenasi suatu lemak bersifat selektif, yaitu lemak dengan derajat ketidakjenuhan lebih tinggi akan lebih mudah terhidrogenasi. Misalnya hidrogenasi lemak yang mengandung linoleat, konversi linoleat menjadi oleat atau isomer isomernya lebih banyak daripada konversi asam oleat menjadi asam stearat.Pada proses hidrogenasi, $\mathrm{H}_{2}$ yang digunakan dialirkan dari tangki penampung $\mathrm{H}_{2}$. Selain itu, pada proses ini juga digunakan katalis Ni yang yang ditempatkan pada packed reactor sebesar $0,02 \%$ dari berat minyak. Kemudian minyak hasil hidrogenasi ditampung dalam tangki penampung hasil hidrogenasi.

Tangki hidrogenasi dilengkapi dengan pengaduk untuk memudahkan minyak bercampur dengan katalis $\mathrm{Ni}$, kondisi operasi pada tangki hidrogenasi adalah pada suhu $180^{\circ} \mathrm{C}$ karena reaksi hidrogenasi mencapai kecepatan maksimum pada suhu tersebut. Selanjutnya minyak tersebut ditampung dalam tangki hasil hidrogenasi. Kemudian minyak dialirkan ke dalam cooler dengan menggunakan pompa untuk menurunkan suhu minyak menjadi $80^{\circ} \mathrm{C}$.

Tahap terakhir yaitu emulsifikasi, tahap ini bertujuan untuk mengemulsi minyak dengan cara penambahan emulsifier untuk pencampuran fase minyak. Terdapat 2 tahap pada proses emulsifikasi yaitu:

a. Proses pencampuran emulsifier fase minyak (EFM)

Emulsifier fase minyak merupakan bahan tambahan yang dapat larut dalam minyak yang berguna untuk menghindari terpisahnya air dari emulsi air minyak terutama dalam penyimpanan. Emulsifier ini mengandung $0,4 \%$ lechitin, $0,3 \% \quad \beta$-karoten, $0,05 \%$ vitamin $\mathrm{A}$, dan $0,005 \%$ vitamin $\mathrm{D}$.

b. Proses pencampuran emulsifier fase cair (EFC)

Emulsifier fase cair merupakan bahan tambahan yang tidak larut dalam minyak. Bahan tambahan ini dicampurkan dalam air yang akan dipakai untuk membuat emulsi dengan minyak. Emulsifier ini terdiri dari garam $(0,4 \%)$, TBHQ $(0,02 \%)$, dan natrium benzoate $(0,1 \%)$.

Pada proses emulsifikasi, minyak dari cooler dengan suhu operasi $80^{\circ} \mathrm{C}$ dialirkan menuju tangki emulsifikasi untuk dilakukan penambahan emulsi fase minyak (EFM) yang berasal dari tangki penampung emulsi fase minyak. Emulsi fase cair dari tangki penampung emulsi fase cair agar didapat margarin dengan komposisi yang diinginkan. Dari tangki emulsifikasi minyak dialirkan menuju tangki pendingin. Tangki pendingin digunakan untuk menurunkan suhu margarin dari suhu $77^{\circ} \mathrm{C}$ sampai suhu $30^{\circ} \mathrm{C}$ pada tekanan 1 atm sehingga produk yang dihasilkan bersifat plastis dan lebih mudah untuk dikemas. Kemudian margarin tersebut dialirkan ke dalam tangki penampungan produk margarin.

\section{MATERIAL BALANCE}

Berdasarkan hasil perhitungan material balance pada pabrik margarin ini dibutuhkan bahan baku antara lain kacang tanah sebanyak 6.192 ton/tahun, 127 ton/tahun emulsifier, dan 20 ton/tahun gas hidrogen untuk menghasilkan produk margarin sebanyak 3.856 ton/tahun dan produk samping bungkil sebanyak $149 \mathrm{~kg} /$ tahun.

\section{ANALISIS EKONOMI}

Dari hasil perhitungan neraca ekonomi, didapatkan Total Capital Investment/modal investasi untuk pabrik ini sebesar Rp 139.524.579.000,00, biaya produksi Rp 126.257.814.000,00/tahun, dengan hasil jual produk Rp 158.096.597.000,00/tahun, Internal Rate of Return sebesar 14,4 \%, Break Event Point 62,05 \%, dan waktu pengembalian modal (Pay Out Time) selama 6 tahun. Pabrik beroperasi secara kontinyu selama 330 hari dan 24 jam.

\section{KESIMPULAN}

Hasil analisis perhitungan pada pra desain pabrik margarin dari kacang tanag dengan proses hidrogenasi diperoleh beberapa kesimpulan antara lain:

- Dari segi teknis : 
- Kapasitas rancangan pabrik margarin direncanakan 3.856 ton/tahun.

- Lokasi pendirian pabrik adalah Kabupaten Tuban, Jawa Timur.

- $\quad$ Bentuk hukum perusahaan yang direncanakan adalah Perseroan Terbatas (PT).

- Bentuk organisasi yang direncanakan adalah organisasi sistem garis dan staf dengan jumlah tenaga kerja yang dibutuhkan sebanyak 124 orang.

- Dari segi ekonomis :

- Modal investasi

: Rp 139.524.579.000,00

- Biaya produksi per tahun : Rp 126.257.814.000,00

- Hasil jual produk per tahun : Rp 158.096.597.000,00

- Internal Rate of Return : : $14,4 \%$

- Pay Out Time : 6 tahun

- Break Even Point : 62,05\%
Dari hasil analisis baik aspek teknis dan ekonomis dapat disimpulkan bahwa pabrik margarin ini layak untuk didirikan.

\section{DAFTAR PUSTAKA}

[1] Marliyati, S. Anna, H. Syarief, D. Muchtadi, L. K. Darusman, and Rimbawan, "Suplementasi Sterol Lembaga Gandum (Triticum sp.) Pada Margarin," J. Teknol. Ind. Pangan, vol. XXI, no. 1, pp. 73-79, 2919.

[2] Balai Pusat Statistika, "Data Ekspor-Impor Kacang Tanah," 2016.

[3] Badan Pusat Statistik, "Data Luas Pertanian, Prodiktivitas, dan Produksi Kacang Tanah Seluruh Provinsi di Indonesia," 2016.

[4] Aparamarta, W. Hakun, S. Teguh, C. Anggita, Y.-H. Ju, and S. Gunawan, "Separation and Purification of Triacylglycerols from Nyamplung (Calophyllum inophyllum) Oil by Batchwise Solvent Extraction," Ind. Eng. Chem. Res, vol. 55, pp. 3113-3119, 2016.

[5] S. Ketaren, Minyak dan Lemak Pangan. Jakarta: UI Press, 1986.

[6] D. Anderson, Bailey's Industrial Oil And Fat Producs Vol.5 6th Edition - Edible Oil and Fat Products: Processing Technologies. New Jersey: John Wiley \& Sons Inc, 2005. 